\title{
Prevention of Nosocomial Infection in the Neurosciences Intensive Care Unit: Remember the Basics
}

\author{
Rob Boots ${ }^{1,2}$
}

Published online: 17 August 2016

(c) Springer Science+Business Media New York 2016

Nosocomial infection remains a major source of morbidity and mortality in intensive care units (ICU) [1]. The case mix in the neurosciences ICU is not immune to such infectious complications [2,3]. Such infections increase both the costs and lengths of stay [4, 5]. Overall mortality rates have progressively improved over the decade, but prevalence remains high despite the advice of the Surviving Sepsis Guidelines [6]. Metrics including ventilatorassociated events, catheter-related urinary tract infections, and catheter-related blood stream infections are accepted performance measures in the ICU [4]. Such infections are often associated with remuneration penalty, particularly in Medicare patients [7-9]. Although specific site of infection risks [10-12] or specific managements are defined [13], they do not necessarily lead to an overall strategy for infection control. Simple but comprehensive, cost-efficient programs [14] of infection control when uniformly and consistently applied reduce such infections in the ICU [15-19].

Murthy and colleagues in this issue of Neurocritical Care have reviewed retrospectively a large cohort of intracranial hemorrhage patients [20]. The prevalence of nosocomial infections was high at $26 \%$, most commonly due to non-neurological infections such as pneumonia, urinary tract infection, and bacteremias. Apart from older

Rob Boots

r.boots@uq.edu.au

1 Department of Intensive Care Medicine, Royal Brisbane and Women's Hospital, Brisbane, Australia

2 Burns Trauma and Critical Care Research Centre, University of Queensland, Brisbane, Australia and sicker patients being more susceptible to such infections, more specific comorbidities were not identified.

In critical care, much has been made of care bundles for routine cares to minimize nosocomial complications $[21,22]$. Although the specific elements of the bundle may not decrease infectious complications, when collectively applied they typically improve outcomes. Their utility depends on their consistent application with auditing for protocol, best practice, and procedural compliance. The article by Halperin and co-investigators gives an account of a return to clinical basics to address unacceptable nosocomial infection rates [23]. The procedure and indications for urinary catheterization were reviewed and patient transport for radiological procedures minimized. This resulted in a marked reduction in both pulmonary and urinary tract infections. The measures applied reflect a comprehensive program of prevention and surveillance incorporated into the prevailing clinical culture.

However, despite all due care, hospitals care for sick patients Long lengths of stay and complex care increase the risks of nosocomial infections. The more complicated the infection control regime, the greater the potential for procedural breeches demanding direct supervision and continuous audit.

The cornerstone of any infection control strategy remains regular hand washing, the use of alcoholic hand rubs and sprays, minimizing jewelry, and bare arms to the elbows. However, achieving good compliance remains elusive [17]. Device insertion requires sterile technique and appropriate aftercare to minimize repeated access, regular site surveillance with insertion site care which ensures the use of bacterial barriers, bacterial filters, and transparent dressings. Peripheral intravenous cannulas should be changed every $72 \mathrm{~h}$ [7]. Minimizing the duration of use of 
indwelling devices and mechanical ventilation is well established to reduce infection rates [22].

Individual patient infection risk reduction requires an understanding of their comorbidities allowing targeted infection control strategies. Patients with advanced pulmonary disease, as an example, should have lung function optimized prior to surgery. This may include preventative regimes of chest physiotherapy, ensuring sputum clearance while minimizing atelectasis [24]. In addition, attention to intraoperative ventilator and fluid use, limiting the extent of surgery where possible, preventing wound infections and pain, and the preemptive use of noninvasive ventilation have documented utility in preventing pulmonary infections [25].

Much of the prevention of nosocomial infection relates to principles of good housekeeping included in the daily care plans with the best supporting evidence in the general ICU population $[26,27]$. A culture of routine surveillance and checklists, customized to the needs of the individual patient, are valuable additions to a clinical review, forming the basis of more formal audits of practice, clinical indicators, and benchmarking [28-30]. Vincent described "FASTHUG" as an approach to routine patient review [31]. This has been validated to improve at least the documentation of care processes. Individual units have developed their own variations of this critical care "housekeeping" to prevent nosocomial complications [32-35]. A culture of regular patient review is inexpensive and creates an environment where attention is focused on the patient in context rather than just management associated with the primary condition such as head injury or intracranial bleed. An expanded approach to such checklist review includes FASTHUG: Feeding and nutrition including route and specific requirements while minimizing the use of parenteral nutrition; Analgesia to ensure pain relive and avoidance of analgesic complications such as constipation and respiratory depression; Sedation/sleep management to improve comfort and reduce delirium; Thromboembolism prophylaxis; Head-up measures to prevent aspiration; Ulcer prophylaxis including stress, decubitus and device related; and Glycemic control. Additionally, ON-FIDDLER prompts for Organ support with review of requirements and settings for cardiovascular and respiratory support; Notification of who needs to know about what, using the most efficient communication method with chart entries having legible dates, times, and signatures; Fluid management including fluid type appropriateness, need for supplementary fluids, and the assessment of fluid deficit or excess; Infection management including isolation requirements, draining collections, surveillance cultures as required with correct antibiotic use, appropriate infection prophylaxis, and antibiotic therapy duration; Dialysis and all things related to the kidney; Lines including all invasive devices, insertion indications, ongoing requirements, timing of removal, appropriate dressings, and surveillance for device-associated complications; Drug review with assessment of drugs the patient is receiving, drugs the patient should be on or should have ceased, and the need for drug sheets rewrites for clarity or drug expiry; Electrolytes and other investigation review; Research with respect to studies the patient is either potentially suitable for or participating in with the aim to understand the study protocol, potential side effects, and protocol violations; radiology and imaging review and rehabilitation including physiotherapy and all things related to discharge planning.

There have been significant reductions in nosocomial infections in surgical patients. Regular application of best clinical practice, attention to routine care "housekeeping" as part of patient review, and audits of compliance with care bundles to ensure consistency of care [36] form a comprehensive strategy to limit rates of potentially preventable infections [37]. It is time to apply this knowledge to the neurosciences ICU, research it, modify it where needed, and audit the results.

\section{References}

1. Rosenthal VD, Maki DG, Mehta Y, et al. International Nosocomial Infection Control Consortium (INICC) report, data summary of 43 countries for 2007-2012. Device-associated module. Am J Infect Control. 2014;42:942-56.

2. Muehlschlegel S, Carandang R, Ouillette C, Hall W, Anderson F, Goldberg R. Frequency and impact of intensive care unit complications on moderate-severe traumatic brain injury: early results of the Outcome Prognostication in Traumatic Brain Injury (OPTIMISM) Study. Neurocrit Care. 2013;18:318-31.

3. Zygun DA, Zuege DJ, Boiteau PJ, et al. Ventilator-associated pneumonia in severe traumatic brain injury. Neurocrit Care. 2006;5:108-14.

4. Profit J, Zupancic JA, Gould JB, et al. Correlation of neonatal intensive care unit performance across multiple measures of quality of care. JAMA Pediatr. 2013;167:47-54.

5. Ohwaki K, Yano E, Nagashima H, Nakagomi T, Tamura A. Impact of infection on length of intensive care unit stay after intracerebral hemorrhage. Neurocrit Care. 2008;8:271-5.

6. Dellinger RP, Levy MM, Rhodes A, et al. Surviving sepsis campaign: international guidelines for management of severe sepsis and septic shock: 2012. Crit Care Med. 2013;41: 580-637.

7. Sagana R, Hyzy RC. Achieving zero central line-associated bloodstream infection rates in your intensive care unit. Crit Care Clin. 2013;29:1-9.

8. Shannon RP, Patel B, Cummins D, Shannon AH, Ganguli G, Lu $\mathrm{Y}$. Economics of central line-associated bloodstream infections. Am J Med Qual. 2006;21:7s-16s.

9. Yi SH, Baggs J, Gould CV, Scott RD 2nd, Jernigan JA. Medicare reimbursement attributable to catheter-associated urinary tract infection in the inpatient setting: a retrospective cohort analysis. Med Care. 2014;52:469-78.

10. Divani AA, Hevesi M, Pulivarthi S, et al. Predictors of nosocomial pneumonia in intracerebral hemorrhage patients: a multi-center observational study. Neurocrit Care. 2015;22: $234-42$. 
11. Liang H, Zhang L, Gao A, et al. Risk factors for infections related to lumbar drainage in spontaneous subarachnoid hemorrhage. Neurocrit Care. 2016. doi:10.1007/s12028-015-0239-1.

12. Babu MA, Patel R, Marsh WR, Wijdicks EF. Strategies to decrease the risk of ventricular catheter infections: a review of the evidence. Neurocrit Care. 2012;16:194-202.

13. Beer R, Pfausler B, Schmutzhard E. Management of nosocomial external ventricular drain-related ventriculomeningitis. Neurocrit Care. 2009;10:363-7.

14. Dick AW, Perencevich EN, Pogorzelska-Maziarz M, Zwanziger J, Larson EL, Stone PW. A decade of investment in infection prevention: a cost-effectiveness analysis. Am J Infect Control. 2015;43:4-9.

15. Alvarez-Moreno CA, Valderrama-Beltran SL, Rosenthal VD, et al. Multicenter study in Colombia: impact of a multidimensional International Nosocomial Infection Control Consortium (INICC) approach on central lineassociated bloodstream infection rates. Am J Infect Control. 2016. doi:10.1016/j.ajic.2016.03.043.

16. Leblebicioglu H, Yalcin AN, Rosenthal VD, et al. Effectiveness of a multidimensional approach for prevention of ventilator-associated pneumonia in 11 adult intensive care units from 10 cities of Turkey: findings of the International Nosocomial Infection Control Consortium (INICC). Infection. 2013;41:447-56.

17. Rosenthal VD, Pawar M, Leblebicioglu H, et al. Impact of the International Nosocomial Infection Control Consortium (INICC) multidimensional hand hygiene approach over 13 years in 51 cities of 19 limited-resource countries from Latin America, Asia, the Middle East, and Europe. Infect Control Hosp Epidemiol. 2013;34:415-23.

18. Rosenthal VD, Ramachandran B, Duenas L, et al. Findings of the International Nosocomial Infection Control Consortium (INICC), Part I: Effectiveness of a multidimensional infection control approach on catheter-associated urinary tract infection rates in pediatric intensive care units of 6 developing countries. Infect Control Hosp Epidemiol. 2012;33:696-703.

19. Rosenthal VD, Todi SK, Alvarez-Moreno C, et al. Impact of a multidimensional infection control strategy on catheter-associated urinary tract infection rates in the adult intensive care units of 15 developing countries: findings of the International Nosocomial Infection Control Consortium (INICC). Infection. 2012;40:517-26.

20. Murthy SB, Moradiya Y, Shah J, et al. Nosocomial infections and outcomes after intracerebral hemorrhage: a population-based study. Neurocrit Care. 2016. doi:10.1007/s12028-016-0282-6.

21. Bukhari SZ, Hussain WM, Banjar AA, Fatani MI, Karima TM, Ashshi AM. Application of ventilator care bundle and its impact on ventilator associated pneumonia incidence rate in the adult intensive care unit. Saudi Med J. 2012;33:278-83.

22. Saloojee H, Steenhoff A. The health professional's role in preventing nosocomial infections. Postgrad Med J. 2001;77:16-9.

23. Halperin JJ, Moran S, Prasek D, Richards A, Ruggiero C, Maund C. Reducing hospital-acquired infections among the neurologically critically Ill. Neurocrit Care. 2016. doi:10.1007/ s12028-016-0286-2.

24. Ntoumenopoulos G, Presneill JJ, McElholum M, Cade JF. Chest physiotherapy for the prevention of ventilator-associated pneumonia. Intensive Care Med. 2002;28:850-6.

25. Canet J, Gallart L. Postoperative respiratory failure: pathogenesis, prediction, and prevention. Curr Opin Crit Care. 2014;20:56-62.

26. Dellinger RP, Levy MM, Carlet JM, et al. Surviving Sepsis Campaign: international guidelines for management of severe sepsis and septic shock: 2008. Crit Care Med. 2008;36:296-327.

27. Schorr CA, Dellinger RP. The Surviving Sepsis Campaign: past, present and future. Trends Mol Med. 2014;20:192-4.

28. Byrnes MC, Schuerer DJ, Schallom ME, et al. Implementation of a mandatory checklist of protocols and objectives improves compliance with a wide range of evidence-based intensive care unit practices. Crit Care Med. 2009;37:2775-81.

29. Carlos WG, Patel DG, Vannostrand KM, Gupta S, Cucci AR, Bosslet GT. Intensive care unit rounding checklist implementation. Effect of accountability measures on physician compliance. Ann Am Thorac Soc. 2015;12:533-8.

30. Cavalcanti AB, Bozza FA, Machado FR, et al. Effect of a quality improvement intervention with daily round checklists, goal setting, and clinician prompting on mortality of critically ill patients: a randomized clinical trial. JAMA. 2016;315:1480-90.

31. Vincent JL. Give your patient a fast hug (at least) once a day. Crit Care Med. 2005;33:1225-9.

32. Curiel Balsera E, Joya Montosa C, Trujillo Garcia E, Martinez Gonzalez MC, Molina Diaz H. [Daily evaluation of the FASTHUG protocol and short-term outcomes]. Med Intensiva/Soc Esp Med Intensiva Unidades Coron. 2014;38:393-4.

33. Mabasa VH, Malyuk DL, Weatherby EM, Chan A. A standardized, structured approach to identifying drug-related problems in the intensive care unit: FASTHUG-MAIDENS. Can J Hosp Pharm. 2011;64:366-9.

34. Masson SC, Mabasa VH, Malyuk DL, Perrott JL. Validity evidence for FASTHUG-MAIDENS, a mnemonic for identifying drug-related problems in the intensive care unit. Can J Hosp Pharm. 2013;66:157-62.

35. Papadimos TJ, Hensley SJ, Duggan JM, et al. Implementation of the "FASTHUG" concept decreases the incidence of ventilatorassociated pneumonia in a surgical intensive care unit. Patient Saf Surg. 2008;2:3.

36. Reiff DA, Shoultz T, Griffin RL, Taylor B, Rue LW 3rd. Use of a bundle checklist combined with physician confirmation reduces risk of nosocomial complications and death in trauma patients compared to documented checklist use alone. Ann Surg. 2015;262:647-52.

37. Cheema AA, Scott AM, Shambaugh KJ, et al. Rebound in ventilator-associated pneumonia rates during a prevention checklist washout period. BMJ Qual Saf. 2011;20:811-7. 